\title{
sciendo
}

\section{DEFECT IN MITOCHONDRIAL NADH-DEHYDROGENASE GENES IN CANINE MAST CELL TUMOURS*}

\author{
Brygida Ślaska ${ }^{\natural}$, Anna Śmiech², Adam Bownik³ ${ }^{3}$ Krzysztof Kowal ${ }^{1}$, Angelika Tkaczyk ${ }^{1}$, \\ Mariusz Pierzchała ${ }^{4}$, Jarosław Dudka ${ }^{5}$ \\ 'Institute of Biological Bases of Animal Production, University of Life Sciences in Lublin, \\ Akademicka 13, 20-950 Lublin, Poland \\ ${ }^{2}$ Sub-Department of Pathomorphology and Forensic Veterinary Medicine, \\ University of Life Sciences in Lublin, Głęboka 30, 20-612 Lublin, Poland \\ ${ }^{3}$ Depertment of Hydrobiology and Protection of Ecosystems, University of Life Sciences in Lublin, \\ Dobrzańskiego 37, 20-262 Lublin, Poland \\ ${ }^{4}$ Department of Genomics and Biodiversity, Institute of Genetics and Animal Breeding, \\ Polish Academy of Sciences, Postępu 36a, 05-552 Jastrzębiec, Poland \\ ${ }^{5}$ Chair and Department of Toxicology, Medical University of Lublin, Jaczewskiego 8b, \\ 20-090 Lublin, Poland \\ •Corresponding author: brygida.slaska@up.lublin.pl
}

\begin{abstract}
Recent studies have demonstrated a significant role of mitochondrial DNA (mtDNA) defects in the pathogenesis of many human and some canine tumours. The aim of this study was to identify mutations in the ND2 and ND4 mitochondrial genes in canine mast cell tumours and determine their association with the process of neoplastic transformation and the phenotypic traits of dogs. In total, 136 gene sequences from 68 biological samples, including blood and neoplastic tissue samples from 34 dogs with diagnosed MCTs, were analysed. The study consisted in DNA sequencing of the ND2 and ND4 genes as well as bioinformatics and statistical analyses. For the first time, mutations in NADH-dehydrogenase genes were detected in dogs with MCTs. In total, 22 polymorphic loci and 19 mutations in the ND2 and ND4 genes were identified. The majority of the identified mutations were homoplasmic, and tumour heteroplasmy was detected in eight nucleotide positions in three dogs. Seven of the ND2 mutations and two of the ND4 mutations caused an amino acid change. The changes in non-synonymous protein-coding SNPs did not exert an adverse effect on proteins. A statistically significant correlation of the presence of mutations/polymorphisms with the sex, age, and size of the dogs and the tumour location was demonstrated. Polymorphisms and mutations in NADH-dehydrogenase genes, including mastocyte-specific changes, in canine mast cell tumours that had not been reported earlier in the literature were identified. Some of these changes may imply that these are the hotspot mutations in canine mast cell tumours. It cannot be excluded that the molecular changes are directly associated with the development of mast cell tumours, and further investigations are needed to verify whether they can become molecular markers of MCTs in the future.
\end{abstract}

Key words: mast cell tumours, dog, genes, mtDNA, mutations

*Work financed from: Institute of Biological Bases of Animal Production, University of Life Sciences in Lublin, Poland. 
In dogs, there is a high risk of development of cutaneous mast cell tumours (MCTs). They account for $7 \%-21 \%$ of all canine skin tumours. Furthermore, MCTs are the most frequent canine skin tumours submitted to histological analyses and diagnosed in veterinary clinics (Welle et al., 2008; Śmiech et al., 2017, 2018). The results presented in the literature indicate a recent increase in the incidence of MCTs in dogs (Śmiech et al., 2016, 2019). The risk of development of the disease varies between breeds. MCTs are most commonly diagnosed in Boxers and Shar-Peis; however, Pugs, Labrador Retrievers, Golden Retrievers, Boston terriers, and Pit-Bulls are frequently affected by these tumours as well. MCTs have been reported sporadically in other dog breeds (Leidinger et al., 2014; Śmiech et al., 2016, 2018, 2019). MCTs diagnosed in Boxers and Pugs are usually low- to medium-grade tumours, whereas a more aggressive course of the disease has been reported in young SharPeis. The multifocal form of MCTs has been reported in Golden Retrievers (Welle et al., 2008; Blackwood et al., 2012).

The aetiology of mast cell tumours has not been elucidated yet, but it is known to be multifactorial (Welle et al., 2008; Śmiech et al., 2016, 2017, 2018, 2019). The current knowledge of the disturbances in the genetic material of MCTs is primarily focused on nuclear DNA. One of the nuclear genes whose mutations and variable expression are indicated to be prognostic indicators for canine MCTs is the c-kit gene, which encodes the receptor tyrosine kinase KIT. It plays a key role in mast cell survival, proliferation, differentiation, and migration (Sledge et al., 2016). Most common internal tandem duplication (ITD) mutations in exon 11 of c-kit have been shown in $20-30 \%$ of canine MCTs. They are more commonly observed in highgrade MCTs compared to low-grade MCTs (Webster et al., 2007; Letard et al., 2008; Vascellari et al., 2013; Sledge et al., 2016). ITD mutations in exons 8 and 9 of c-kit have been identified in less than 5\% of MCTs (Letard et al., 2008; Sledge et al., 2016). In MCTs, differences in the patterns of expression of KIT, Ki67, BCL-2, and COX-2 have been reported as well (Webster et al., 2006; Sledge et al., 2016). It has been shown that mutations in c-kit are associated with aberrant KIT protein localization. However, not all MCTs with aberrant KIT protein localization have mutations in the c-kit gene (Webster et al., 2006; Sledge et al., 2016). Vascellari et al. (2013) have described the expression of Ki67, BCL-2, and COX-2 in canine MCTs. They found that only the expression of the Ki67 protein was significantly associated with grading and survival. Additionally, they noted that the increased BCL-2 mRNA level was significantly associated with an increased mortality rate and COX-2 mRNA was significantly up-regulated in MCTs, compared to surgical margins and control skin tissue (Vascellari et al., 2013).

Besides the nuclear genome disorders in MCTs, the still unclear role of mutations in mitochondrial DNA (mtDNA) that may be associated with the development of these tumours has started to be highlighted (Śmiech et al., 2016, 2019). The involvement of mitochondria in the neoplastic process was first described by Warburg in 1932. He supported his hypothesis by indication of the predominance of anaerobic glycolysis in the tumour cell. The interest in the role of mitochondria in the carcinogenesis process is also associated with the finding of respiratory deficit, especially in cells with accelerated proliferation. The respiratory deficit is thought to affect sub- 
sequent cell differentiation and cause neoplastic transformation (Ślaska et al., 2013; Grzybowska-Szatkowska and Ślaska, 2014).

The complete nucleotide sequence of the mitochondrial genome of the domestic dog Canis familiaris comprises 16728 base pairs (bp), with a 1270-bp long control region (Kim et al., 1998). Two chains of mtDNA, both light and heavy, are coding chains. The total number of genes in canine mtDNA is 37, including 22 genes encoding tRNA molecules, 2 genes encoding rRNA, and 13 genes involved in the oxidative phosphorylation (OXPHOS) process. Proteins encoded by these genes belong to complexes I, III, IV, and V (Kim et al., 1998). Complex I is reduced nicotinamide adenine dinucleotide (NADH) dehydrogenase-ubiquinone oxidoreductase. Its task is to transport reducing equivalents from a reduced form of NADH to ubiquinone (coenzyme Q-CoQ). Mutations in the OXPHOS gene of mitochondrial DNA cause disturbances in electron transport via the respiratory chain (Grzybowska-Szatkowska and Ślaska, 2014; Grzybowska-Szatkowska et al., 2014).

The relationship between mutations in mitochondrial DNA (mtDNA) and carcinogenesis in humans has been investigated since the end of the 1980s. Recent studies suggest that changes in the human mtDNA content can be a prognostic factor for breast and lung cancer as well as Hodgkin's lymphoma (Ślaska et al., 2013; Grzybowska-Szatkowska and Ślaska, 2014; Grzybowska-Szatkowska et al., 2014). Similar analyses in dogs have been conducted for only a few years (Ślaska et al., 2013, 2014, 2016; Slaska et al., 2015; Śmiech et al., 2016, 2019; Surdyka and Slaska, 2017 $\mathrm{a}$ b). Somatic mutations in coding regions and D-loops have been detected in various types of canine tumours. However, investigations of mastocytes have been limited only to the mtDNA non-coding region - the D-loop and one cytochrome b $(C Y B)$ gene. Researchers have found associations of mutations and polymorphisms of the hypervariable regions of mtDNA (Śmiech et al., 2016) and the CYB gene (Śmiech et al., 2019) with canine mast cell tumours. To date, there are no more reports on the defects in the mtDNA coding regions in canine MCTs that determine carcinogenesis, as in the case of humans. In human mtDNA, mitochondrial NADH dehydrogenase polymorphisms have been related to breast cancer (Grzybowska-Szatkowska and Ślaska, 2014).

Data on the human mitochondrial genome demonstrate that there are 92 mutations in the ND2 gene and 152 mutations in the ND4 gene in complex I in different human tumours (Lu et al., 2009). Since there have been no similar investigations on canine mastocytes, the aim of this study was to identify mutations in mitochondrial genes ND2 and ND4 in canine mast cell tumours and determine their association with the process of neoplastic transformation and phenotypic traits in dogs.

\section{Material and methods}

\section{Animals}

We analysed 136 gene sequences in 34 dogs diagnosed with MCTs. Sixty-eight samples obtained from blood $(n=68)$ and tumour tissues $(n=68)$ of 34 dogs of different breeds were analysed (Table 1). 
Table 1. Data on dogs with mast cell tumours included in the study

\begin{tabular}{|c|c|c|c|c|c|c|}
\hline $\begin{array}{c}\text { Number } \\
\text { of dog }\end{array}$ & Sex & Breed/crossbreed & $\begin{array}{c}\text { Age } \\
\text { (years) }\end{array}$ & $\begin{array}{l}\text { Grading according } \\
\text { to Kiupel et al. (2011) }\end{array}$ & Location & Size \\
\hline 1 & $\mathrm{~F}$ & Boxer & 8 & Low-grade & ear & $\mathrm{S}$ \\
\hline 2 & $\mathrm{M}$ & Golden Retriever & 7 & Low-grade & torso & $\mathrm{L}$ \\
\hline 3 & $\mathrm{M}$ & Crossbreed & 15 & High-grade & neck & $\mathrm{S}$ \\
\hline 4 & $\mathrm{M}$ & Labrador & 7 & Low-grade & pelvic limb & M \\
\hline 5 & $\mathrm{~F}$ & Dachshund & 9 & High-grade & ear & $\mathrm{S}$ \\
\hline 6 & $\mathrm{~F}$ & Labrador & 4 & Low-grade & neck & M \\
\hline 7 & $\mathrm{M}$ & American Staffordshire Terrier & 8 & Low-grade & rib region & M \\
\hline 8 & $\mathrm{~F}$ & Bernese Mountain Dog & 9 & High-grade & parapet & $\mathrm{L}$ \\
\hline 9 & $\mathrm{~F}$ & Cane Corso & 8 & High-grade & thigh & $\mathrm{L}$ \\
\hline 10 & $\mathrm{~F}$ & American Staffordshire Terrier & 8 & Low-grade & thigh & M \\
\hline 11 & $\mathrm{~F}$ & Labrador & 6 & High-grade & torso & M \\
\hline 12 & $\mathrm{~F}$ & German Shepherd & 8 & Low-grade & wrist & $\mathrm{L}$ \\
\hline 13 & $\mathrm{~F}$ & Central Asian Shepherd & 4 & High-grade & lip & $\mathrm{L}$ \\
\hline 14 & $\mathrm{M}$ & Alaskan malamute & 6 & Low-grade & rib region & M \\
\hline 15 & $\mathrm{~F}$ & German Pointer & 10 & Low-grade & thigh & $\mathrm{L}$ \\
\hline 16 & $\mathrm{~F}$ & Labrador & 5 & Low-grade & neck & M \\
\hline 17 & $\mathrm{M}$ & Labrador & 8 & High-grade & cheek & M \\
\hline 18 & $\mathrm{~F}$ & Bull Terrier & 8 & Low-grade & ear & M \\
\hline 19 & $\mathrm{~F}$ & Golden Retriever & 12 & Low-grade & torso & $\mathrm{L}$ \\
\hline 20 & $\mathrm{~F}$ & Bavarian Mountain Hound & 9 & High-grade & rib region & M \\
\hline 21 & $\mathrm{~F}$ & St. Bernard & 6 & High-grade & neck & $\mathrm{L}$ \\
\hline 22 & $\mathrm{M}$ & French Bulldog & 10 & Low-grade & scrotum & S \\
\hline 23 & $\mathrm{~F}$ & Crossbreed & 6 & Low-grade & neck & $\mathrm{S}$ \\
\hline 24 & $\mathrm{M}$ & Boxer & 8 & Low-grade & wrist & S \\
\hline 25 & $\mathrm{~F}$ & Miniature Schnauzer & 8 & Low-grade & elbow & $\mathrm{S}$ \\
\hline 26 & $\mathrm{~F}$ & Boxer & 8 & Low-grade & ear & S \\
\hline 27 & $\mathrm{~F}$ & Crossbreed & 15 & High-grade & rib region & $\mathrm{S}$ \\
\hline 28 & $\mathrm{~F}$ & Bernese Mountain Dog & 8 & High-grade & wrist & $\mathrm{L}$ \\
\hline 29 & $\mathrm{M}$ & French Bulldog & 7 & High-grade & scrotum & S \\
\hline 30 & $\mathrm{M}$ & Shar-pei & 8 & High-grade & rib region & M \\
\hline 31 & $\mathrm{~F}$ & Golden Retriever & 4 & Low-grade & $\begin{array}{l}\text { gluteal } \\
\text { region }\end{array}$ & $\mathrm{L}$ \\
\hline 32 & $\mathrm{M}$ & Labrador & 10 & Low-grade & neck & M \\
\hline 33 & $\mathrm{~F}$ & Crossbreed & 11 & Low-grade & parapet & $\mathrm{S}$ \\
\hline 34 & $\mathrm{M}$ & Crossbreed & 13 & Low-grade & $\begin{array}{l}\text { thoracic } \\
\text { limb }\end{array}$ & S \\
\hline
\end{tabular}

\section{Laboratory procedures}

The analyses were performed on DNA isolated from post-operative tissues: tumour tissues and blood samples from dogs with diagnosed MCTs. Tumour tissues 
were sampled for histopathology analysis, fixed in buffered formalin, $\mathrm{pH}=7.2$, processed routinely, embedded in paraffin wax, sectioned into 4- $\mu \mathrm{m}$ thick fragments, and stained with haematoxylin-eosin and toluidine blue. Microscopic classification was performed in accordance with the WHO histological classification (Hendrick et al., 1998). The degree of malignancy was assessed using a 2-grade scale (Kiupel et al., 2011).

DNA was extracted from tumour tissue and blood with the DNeasy Blood \& Tissue Kit (Qiagen, Hilden, Germany). DNA samples were assessed quantitatively and qualitatively by electrophoretic separation in agarose gel and spectrophotometrically (BioPhotometer, Eppendorf, Hamburg, Germany). Amplification of genes ND2 and ND4 was performed using the polymerase chain reaction (PCR) technique in a T100 Thermal Cycler (Bio-Rad, Wrocław, Poland). Primer sequences used in the analysis encompassed the mitochondrial gene ND2 (NADH dehydrogenase subunit 2) (1042 bp (base pair) fragment) and ND4 (NADH dehydrogenase subunit 4) (782 bp fragment). The PCR primers were used as in Surdyka and Slaska (2017 b) (ND2F: 5'CCTCCTTTACTCCGGCCAATGGGT3' and ND2R: 5'GCGGTGCTATATGTGAGTCGCAGG3' - mtDNA fragment position: m.3914-m.4955) and as in Ślaska et al. (2014) (ND4F: 5' ATCCAGCCTCTGCCAAACTC 3' and ND4R: 5' GGCAGTAGGTGCAAGGTCAT 3' (mtDNA fragment position (bp): 1074711528). The annealing temperature for the analysed genes was $58.5^{\circ} \mathrm{C}$. The amplicons were sequenced using a BigDye Terminator Cycle Sequencing kit (Applied Biosystems, Foster City, CA, USA) in GeneAmp PCR system 9700 (Applied Biosystems). Extension products were separated on an ABI 377 automated sequencer (Applied Biosystems). The amplicons were subjected to bioinformatics analyses (DNA Baser Sequence Assembler 3.2, 2012; Kumar et al., 2016). The loci in the nucleotide sequence were determined by comparison of the analysed sequences with the reference sequence (GenBank accession No. U96639 (Kim et al., 1998). The polymorphisms involved changes occurring in tumour and blood cells from the same dog in comparison with the reference sequence. A mutation is a change characteristic for tumour cells but not present in blood.

\section{Bioinformatics analysis}

The dogs were divided into three size groups: (1) small (S, estimated wither height - ewh: 30-45 cm), (2) medium (M, ewh: 45-60 cm), and (3) large (L, ewh: $>60 \mathrm{~cm}$ ) (Pionnier-Capitan et al., 2011). They were also divided into three groups according to age: (1) dogs up to 6 years, (2) from 6 to 7 years, and (3) 9 years old and over. According to the location of the tumour, the dogs were divided into three groups: MCTs located (1) on the torso, (2) on the head and neck, and (3) on the extremities.

Frequencies were determined using the SAS 9.4 procedure PROCFREQ (SAS Institute, Cary, NC, USA). The probability of occurrence of polymorphisms and mutations in each locus and in all polymorphic/mutation loci depending on the malignancy grade (low-grade; high grade), sex, size, and age of the dogs as well as the tumour location was estimated using the method of least-squares means (lsm+se (standard error)). The association between the data was analysed using the SAS 9.4 
procedure PROC GLM (SAS Institute, Cary, NC, USA). Associations with $\mathrm{P} \leq 0.05$ were considered significant.

The probability of deleterious mutations, i.e. a functional effect of the non-synonymous protein-coding SNP, was determined using the Panther Classification System (Tang and Thomas, 2016). It predicts disease-causing genetic variants using position-specific evolutionary preservation. The ExPASy Server (Gasteiger et al., 2005) was used to characterise such physicochemical parameters as the theoretical isoelectric point (pI), instability index, aliphatic index, and grand average hydropathy (GRAVY). SOPMA was used for calculation of the secondary structural features of antioxidant protein sequences. Trans Membrane prediction using the Hidden Markov Model (TMHMM) was used for predicting transmembrane helices based on the Hidden Markov Model (Combet et al., 2000).

The HGVS (2016) nomenclature was used for description of variants of sequences found in the DNA and proteins.

\section{Results}

The encoding sequences of the canine ND2 and ND4 genes were deposited in the GenBank with accession numbers MK580463 and MK580464, respectively.

\section{ND2 gene}

Somatic mutations and/or polymorphisms in the ND2 gene sequence were detected in 14 nucleotide positions in over $76 \%$ of the dogs with MCTs, with mutations observed in $35 \%$ of all the dogs (Tables 2 and 3 ). The mutations were detected in 12 nucleotide positions of the ND2 gene in the blood and/or tumour tissue of the examined dogs (Table 2). There were from 1 to 5 mutations in the ND2 gene (Table 2). Most of the mutations were homoplasmic, whereas heteroplasmy was detected in two positions $(\mathrm{m} .4303 \mathrm{G}>\mathrm{A} / \mathrm{G}, \mathrm{m} .4440 \mathrm{G}>\mathrm{A} / \mathrm{G})$ in only one dog. All the changes were substitution mutations.

Six of the twelve mutations identified in the ND2 gene sequence of canine MCTs resulted in a change in the protein amino acid (Table 2). Homoplasmic mutations of the ND2 gene, i.e. m.4169A $>\mathrm{G}$, which caused isoleucine-to-valine substitution (p.(Ile86Val)), and $\mathrm{m} .4572 \mathrm{~T}>\mathrm{C}$ resulting in methionine-to-threonine substitution (p.(Met220Thr)), were detected in a low-grade mast cell tumour from a Boxer. A substitution of arginine with glutamine (p.(Arg176Gln)) was a result of a heteroplasmic mutation in $\mathrm{m} .4440 \mathrm{G}>\mathrm{A} / \mathrm{G}$, whereas a mutation in $\mathrm{m} .4503 \mathrm{G}>\mathrm{A}$ resulted in an asparagine-to-serine substitution (p.(Asn197Ser)) in the ND2 protein in dogs with low-grade MCTs. Mutation $\mathrm{m} .4277 \mathrm{G}>\mathrm{A}$ resulted in a substitution of isoleucine with valine (p.(Ile122 Val)), whereas mutation $\mathrm{m} .4517 \mathrm{~A}>\mathrm{G}$ led to a substitution of valine with isoleucine (p.(Val202Ile)) in the ND2 protein (Table 1 and 2).

The occurrence of polymorphisms in the blood of dogs with MCTs was noted in ten positions of the ND2 gene in over $40 \%$ of the examined dogs (Table 3 ). Five polymorphisms (m.4169A $>$ G, m.4277A $>$ G, m.4466G $>$ A, m.4517G $>$ A, m.4572T $>$ C) resulted in amino acid change (p.(Ile86Val), p.(Ile122Val), p.(Ala185Thr), p.(Val202Ile), and p.(Met220Thr), respectively) (Table 3). 
Table 2. Somatic mutations in the ND2 and ND4 gene sequences in blood and tumour tissue in cases of canine mast cell tumours

\begin{tabular}{c|c|c|c|c|c}
\hline $\begin{array}{c}\text { Number } \\
\text { of dog }\end{array}$ & $\begin{array}{c}\text { Grading according } \\
\text { to Kiupel et al. } \\
(2011)\end{array}$ & $\begin{array}{c}\text { Sequences } \\
\text { in dog's blood }\end{array}$ & $\begin{array}{c}\text { Sequences } \\
\text { in cancer cells }\end{array}$ & $\begin{array}{c}\text { Amino acid } \\
\text { change }\end{array}$ & Codon change \\
\hline 1 & 2 & 3 & 4 & 5 & 6 \\
\hline
\end{tabular}

\section{ND2 gene}

1

2

3

10 Low-grade

11 High-grade

13 High-grade

15 Low-grade

19 Low-grade

21 High-grade

25 Low-grade

27 High-grade

\begin{tabular}{|c|c|c|c|}
\hline $\mathrm{m} .4572 \mathrm{~T}$ & $\mathrm{~m} .4572 \mathrm{C}$ & p.(Met220Thr) & $\mathrm{ATA} \rightarrow \mathrm{ACA}$ \\
\hline m.4169A & $\mathrm{m} .4169 \mathrm{G}$ & p.(Ile86Val) & $\mathrm{ATC} \rightarrow \mathrm{GTC}$ \\
\hline $\mathrm{m} .4303 \mathrm{G}$ & $\mathrm{m} .4303 \mathrm{~A}$ & p. $($ Leu130=) & $\mathrm{CTA} \rightarrow \mathrm{CTG}$ \\
\hline m.4204A & $\mathrm{m} .4204 \mathrm{G}$ & p. $($ Met $97=)$ & $\mathrm{ATG} \rightarrow \mathrm{ATA}$ \\
\hline $\mathrm{m} .4277 \mathrm{G}$ & $\mathrm{m} .4277 \mathrm{~A}$ & p.(Ile122Val) & $\mathrm{ATT} \rightarrow \mathrm{GTT}$ \\
\hline $\mathrm{m} .4390 \mathrm{C}$ & $\mathrm{m} .4390 \mathrm{~T}$ & p.(Leu159=) & $\mathrm{CTT} \rightarrow \mathrm{CTC}$ \\
\hline $\mathrm{m} .4517 \mathrm{~A}$ & $\mathrm{~m} .4517 \mathrm{G}$ & p.(Val202Ile) & $\mathrm{GTT} \rightarrow \mathrm{ATT}$ \\
\hline $\mathrm{m} .4646 \mathrm{C}$ & $\mathrm{m} .4646 \mathrm{~T}$ & p. $($ Leu $245=)$ & $\mathrm{TTA} \rightarrow \mathrm{CTA}$ \\
\hline $\mathrm{m} .4303 \mathrm{G}$ & $\mathrm{m} .4303 \mathrm{~A}$ & p. $($ Leu130=) & $\mathrm{CTA} \rightarrow \mathrm{CTG}$ \\
\hline $\mathrm{m} .4366 \mathrm{C}$ & $\mathrm{m} .4366 \mathrm{~T}$ & p. $($ Thr151=) & $\mathrm{ACT} \rightarrow \mathrm{ACC}$ \\
\hline $\mathrm{m} .4303 \mathrm{G}$ & $\mathrm{m} .4303 \mathrm{~A}$ & p. $($ Leu130=) & $\mathrm{CTA} \rightarrow \mathrm{CTG}$ \\
\hline $\mathrm{m} .4204 \mathrm{G}$ & $\mathrm{m} .4204 \mathrm{~A}$ & p. $($ Met97=) & $\mathrm{ATG} \rightarrow \mathrm{ATA}$ \\
\hline $\mathrm{m} .4277 \mathrm{~A}$ & $\mathrm{~m} .4277 \mathrm{G}$ & p.(Ile122Val) & $\mathrm{ATT} \rightarrow \mathrm{GTT}$ \\
\hline $\mathrm{m} .4390 \mathrm{~T}$ & $\mathrm{~m} .4390 \mathrm{C}$ & p.(Leu159=) & $\mathrm{CTT} \rightarrow \mathrm{CTC}$ \\
\hline $\mathrm{m} .4517 \mathrm{G}$ & $\mathrm{m} .4517 \mathrm{~A}$ & p.(Val202Ile) & $\mathrm{GTT} \rightarrow \mathrm{ATT}$ \\
\hline $\mathrm{m} .4646 \mathrm{~T}$ & $\mathrm{~m} .4646 \mathrm{C}$ & p. $($ Leu $245=)$ & $\mathrm{TTA} \rightarrow \mathrm{CTA}$ \\
\hline $\mathrm{m} .4303 \mathrm{~A}$ & $\mathrm{~m} .4303 \mathrm{G}$ & p. $($ Leu $130=)$ & $\mathrm{CTA} \rightarrow \mathrm{CTG}$ \\
\hline $\mathrm{m} .4234 \mathrm{~T}$ & $\mathrm{~m} .4234 \mathrm{C}$ & p.(Gly107=) & $\mathrm{GGC} \rightarrow \mathrm{GGT}$ \\
\hline $\mathrm{m} .4503 \mathrm{G}$ & $\mathrm{m} .4503 \mathrm{~A}$ & p.(Asn197Ser) & $\mathrm{AAC} \rightarrow \mathrm{AGC}$ \\
\hline m. 4517A & $\mathrm{m} .4517 \mathrm{G}$ & p.(Val202Ile) & $\mathrm{GTT} \rightarrow \mathrm{ATT}$ \\
\hline $\mathrm{m} .4277 \mathrm{G}$ & $\mathrm{m} .4277 \mathrm{~A}$ & p.(Ile122Val) & $\mathrm{ATT} \rightarrow \mathrm{GTT}$ \\
\hline m.4390C & $\mathrm{m} .4390 \mathrm{~T}$ & p.(Leu159=) & $\mathrm{CTT} \rightarrow \mathrm{CTC}$ \\
\hline m. 4517A & $\mathrm{m} .4517 \mathrm{G}$ & p.(Val202Ile) & $\mathrm{GTT} \rightarrow \mathrm{ATT}$ \\
\hline m. 4646C & $\mathrm{m} .4646 \mathrm{~T}$ & p. $($ Leu $245=)$ & $\mathrm{TTA} \rightarrow \mathrm{CTA}$ \\
\hline m. $4303 \mathrm{~A}$ & m. $4303 \mathrm{G}$ & p. $($ Leu130=) & $\mathrm{CTA} \rightarrow \mathrm{CTG}$ \\
\hline $\mathrm{m} .4277 \mathrm{G}$ & $\mathrm{m} .4277 \mathrm{~A}$ & p.(Ile122Val) & $\mathrm{ATT} \rightarrow \mathrm{GTT}$ \\
\hline m. $4390 \mathrm{C}$ & $\mathrm{m} .4390 \mathrm{~T}$ & p. $($ Leu159=) & $\mathrm{CTT} \rightarrow \mathrm{CTC}$ \\
\hline m. 4517A & $\mathrm{m} .4517 \mathrm{G}$ & p.(Val202Ile) & $\mathrm{GTT} \rightarrow \mathrm{ATT}$ \\
\hline m. 4646C & $\mathrm{m} .4646 \mathrm{~T}$ & p. $($ Leu $245=)$ & $\mathrm{TTA} \rightarrow \mathrm{CTA}$ \\
\hline m.4303A & $\mathrm{m} .4303 \mathrm{G}$ & p. $($ Leu130=) & $\mathrm{CTA} \rightarrow \mathrm{CTG}$ \\
\hline $\mathrm{m} .4277 \mathrm{G}$ & $\mathrm{m} .4277 \mathrm{~A}$ & p.(Ile122Val) & $\mathrm{ATT} \rightarrow \mathrm{GTT}$ \\
\hline m. 4390C & $\mathrm{m} .4390 \mathrm{~T}$ & p. $($ Leu159=) & $\mathrm{CTT} \rightarrow \mathrm{CTC}$ \\
\hline m. 4517A & $\mathrm{m} .4517 \mathrm{G}$ & p.(Val202Ile) & $\mathrm{GTT} \rightarrow \mathrm{ATT}$ \\
\hline m. 4646C & $\mathrm{m} .4646 \mathrm{~T}$ & p.(Leu245=) & $\mathrm{TTA} \rightarrow \mathrm{CTA}$ \\
\hline
\end{tabular}


Table 2 - contd.

\begin{tabular}{c|c|c|c|c|c}
\hline 1 & 2 & 3 & 4 & 5 & 6 \\
\hline 34 & Low-grade & $\mathrm{m} .4303 \mathrm{G}$ & $\mathrm{m} .4303 \mathrm{~A} / \mathrm{G}^{*}$ & $\mathrm{p} .(\mathrm{Leu} 130=)$ & CTA $\rightarrow$ CTG \\
& & $\mathrm{m} .4440 \mathrm{G}$ & $\mathrm{m} .4440 \mathrm{~A} / \mathrm{G}^{*}$ & $\mathrm{p} .(\operatorname{Arg} 176 \mathrm{Gln})$ & CGA $\rightarrow$ CAA
\end{tabular}

\section{ND4 gene}

\begin{tabular}{|c|c|c|c|c|c|}
\hline \multirow[t]{2}{*}{1} & \multirow[t]{2}{*}{ Low-grade } & m.10992G & m.10992A & p.(Leu264=) & $\mathrm{TTG} \rightarrow \mathrm{TTA}$ \\
\hline & & m.11172A & $\mathrm{m} .11172 \mathrm{G}$ & p.(Ser324=) & $\mathrm{TCA} \rightarrow \mathrm{TCG}$ \\
\hline 2 & Low-grade & m.10992A & m.10992G & p.(Leu264=) & $\mathrm{TTG} \rightarrow \mathrm{TTA}$ \\
\hline \multirow[t]{5}{*}{3} & High-grade & m.10917A & m.10917G & p.(Gly239=) & $\mathrm{GGG} \rightarrow \mathrm{GGA}$ \\
\hline & & m.10992A & m.10992G & p.(Leu264=) & $\mathrm{TTG} \rightarrow \mathrm{TTA}$ \\
\hline & & $\mathrm{m} .11176 \mathrm{~T}$ & m.11176C & p. $($ Leu326=) & $\mathrm{CTA} \rightarrow \mathrm{TTA}$ \\
\hline & & m.11250C & $\mathrm{m} .11250 \mathrm{~T}$ & p. $($ Thr350=) & $\mathrm{ACT} \rightarrow \mathrm{ACC}$ \\
\hline & & m.11402C & $\mathrm{m} .11402 \mathrm{~T}$ & p.(Ile401Thr) & $\mathrm{ATC} \rightarrow \mathrm{ACC}$ \\
\hline \multirow[t]{5}{*}{7} & Low-grade & m.10917A & m.10917G & p.(Gly239=) & $\mathrm{GGG} \rightarrow \mathrm{GGA}$ \\
\hline & & m.10992A & m.10992G & p.(Leu264=) & $\mathrm{TTG} \rightarrow \mathrm{TTA}$ \\
\hline & & $\mathrm{m} .11176 \mathrm{~T}$ & $\mathrm{~m} .11176 \mathrm{C}$ & p.(Leu326=) & $\mathrm{CTA} \rightarrow \mathrm{TTA}$ \\
\hline & & m.11250C & $\mathrm{m} .11250 \mathrm{~T}$ & p. $($ Thr350=) & $\mathrm{ACT} \rightarrow \mathrm{ACC}$ \\
\hline & & m.11402C & $\mathrm{m} .11402 \mathrm{~T}$ & p.(Ile401Thr) & $\mathrm{ATC} \rightarrow \mathrm{ACC}$ \\
\hline \multirow[t]{2}{*}{8} & High-grade & m.10992A & m.10992G & p.(Leu264=) & $\mathrm{TTG} \rightarrow \mathrm{TTA}$ \\
\hline & & m.11172G & $\mathrm{m} .11172 \mathrm{~A}$ & p.(Ser324=) & $\mathrm{TCA} \rightarrow \mathrm{TCG}$ \\
\hline 9 & High-grade & m.10992A & m.10992G & p.(Leu264=) & $\mathrm{TTG} \rightarrow \mathrm{TTA}$ \\
\hline 12 & Low-grade & m.11241A & m.11241C & p.(Gly347=) & $\mathrm{GGA} \rightarrow \mathrm{GGC}$ \\
\hline 13 & High-grade & m.11241A & m.11241C & p.(Gly347=) & $\mathrm{GGA} \rightarrow \mathrm{GGC}$ \\
\hline \multirow[t]{5}{*}{19} & Low-grade & m.10917A & m.10917A/G* & p.(Gly239=) & $\mathrm{GGG} \rightarrow \mathrm{GGA}$ \\
\hline & & m.11172A & $\mathrm{m} .11172 \mathrm{~A} / \mathrm{G}^{*}$ & p.(Ser324=) & $\mathrm{TCA} \rightarrow \mathrm{TCG}$ \\
\hline & & $\mathrm{m} .11176 \mathrm{~T}$ & $\mathrm{~m} .11176 \mathrm{~T} / \mathrm{C}^{*}$ & p.(Leu326=) & $\mathrm{CTA} \rightarrow \mathrm{TTA}$ \\
\hline & & m.11250C & $\mathrm{m} .11250 \mathrm{~T} / \mathrm{C}^{*}$ & p. $($ Thr350=) & $\mathrm{ACT} \rightarrow \mathrm{ACC}$ \\
\hline & & m.11402C & m.11402 T/C* & p.(Ile401Thr) & $\mathrm{ATC} \rightarrow \mathrm{ACC}$ \\
\hline 33 & Low-grade & m.10992A & m.10992 A/G* & p.(Leu264=) & $\mathrm{TTG} \rightarrow \mathrm{TTA}$ \\
\hline
\end{tabular}

*heteroplasmy.

The GLM analyses revealed that the probability of occurrence of polymorphisms as well as nucleotide changes (mutations and polymorphisms) in position $\mathrm{m} .4204$ was significantly higher in males than in females $(\mathrm{P}=0.0340, \mathrm{P}=0.0094$, respectively). The probability of occurrence of nucleotide changes was significantly lower $(\mathrm{P}=0.0272)$ in the youngest dogs than in the middle-aged dogs. Furthermore, the probability of nucleotide changes in the ND2 gene sequence in position m.4303 exhibited a statistically significant correlation with the location of MCTs and was significantly higher $(\mathrm{P}=0.0423, \mathrm{P}=0.0490$, respectively $)$ in the case of mast cell tumours located on the extremities than those located on the torso. There were no significant correlations between the mutations and polymorphisms of the ND2 gene with the MCT malignancy grade or the size of the dogs. 


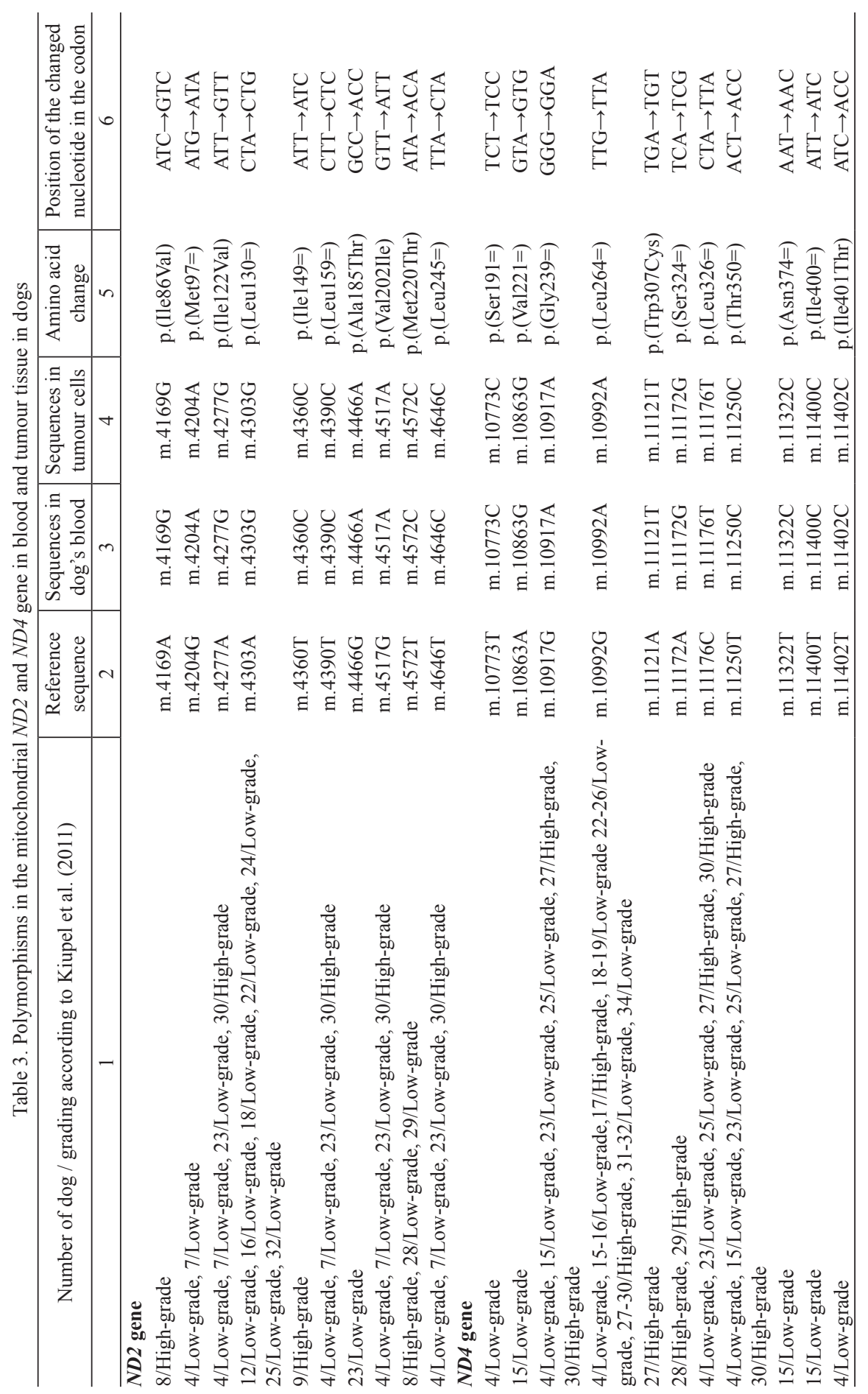




\section{ND4 gene}

Somatic mutations and/or polymorphisms in the ND4 gene sequence were found in 12 positions in almost $80 \%$ of the dogs with MCTs, with mutations observed in over $32 \%$ of all the dogs (Table 2 and 3 ). The mutations were detected in seven nucleotide positions of the ND4 gene in the blood and/or tumour tissue of the examined dogs (Table 2). Most of these changes were homoplasmic substitution mutations. Heteroplasmy was detected in only two dogs: in five positions of the ND4 gene sequence in a 12-year-old Golden Retriever and in one position in an 11-year-old crossbreed dog (Table 2). Somatic mutations or polymorphisms in position m.10992 in the ND4 gene were identified in over $73 \%$ of the dogs (Tables 2 and 3).

One of the seven mutations detected in the canine MCTs resulted in a change in the protein amino acid. A non-synonymous homoplasmic mutation in the ND4 gene - m.11402T $>$ C caused isoleucine-to-threonine substitution (p.(Ile401Thr)) in three dogs. Synonymous mutations were identified in the other dogs presented in Table 2.

Polymorphisms were detected in 11 nucleotide sequences in the gene ND4 sequence (Table 3). The dogs with MCTs presented in Table 3 were characterised by the occurrence of 1 to 6 polymorphisms in the blood and tumour tissue, in relation to the reference sequence. Two of the polymorphisms (m.11121A $>\mathrm{T}$ and $\mathrm{m} .11402 \mathrm{~T}>\mathrm{C})$ resulted in a change in the protein amino acid (p.(Trp307Cys) and p.(Ile401Thr), respectively) (Table 3 ).

The results of the GLM procedure indicate that the probability of mutations and polymorphisms in position m.10992 of the ND4 gene was significantly higher in males than in females $(\mathrm{P}=0.0449)$. The probability of occurrence of nucleotide changes in the ND4 gene sequence and in position m.10992 was statistically significantly correlated with the age of the dogs and was significantly lower $(\mathrm{P}=0.0378, \mathrm{P}=0.0166$, respectively) in the youngest dogs than in the middle-aged dogs. Additionally, the mutations and polymorphisms in position $\mathrm{m}$. 11172 exhibited significantly higher frequency $(\mathrm{P}=0.0309)$ in the large breeds, compared to the medium-sized dogs. There were no significant correlations between the mutations and polymorphisms of the ND4 gene and the MCT malignancy grade or tumour location.

\section{Effect of the non-synonymous protein-coding SNP}

The probability of deleterious mutations, i.e. a functional effect of the non-synonymous protein-coding SNP (Tables 2 and 3), which was determined using the Panther Classification System, indicates that the substitutions in the ND2 protein (p.(Arg176Gln) and p.(Ala185Thr)) may disrupt protein function. Each of the changes was detected in only one crossbreed dog with a low-grade MCT. The other nonsynonymous protein-coding SNP substitutions described (Tables 2 and 3) are more likely not to disrupt the protein function.

The effect of non-synonymous protein-coding SNP on the structure and function of the protein is shown in Table 4 . The possible effect of non-synonymous mutations reflected in amino acid changes in the protein was assessed. The value of the isoelectric point (pI) of the protein encoded by genes ND2 and ND4 indicates their acidic character. The $\mathrm{pI}$ value was not changed by the amino acid substitution in any of the analysed cases. The aliphatic index, which is regarded as a positive factor 
increasing the thermal stability of globular proteins, was not changed in the case of the non-synonymous protein-coding SNP of the ND2 and ND4 genes. The analyses showed that the amino acid changes in ND2 and ND4 did not alter protein stability. No significant changes were observed in the value of the GRAVY parameter, whose positive value indicates a hydrophobic nature of the protein. The analysis of the secondary structure was performed to determine whether a given amino acid lies in a helix strand or a coil. The secondary structural features predicted by SOPMA are presented in Table 5.

Table 4. Comparison of protein properties in non-synonymous protein-coding SNP in dogs with the tumour

\begin{tabular}{lccccc}
\hline $\begin{array}{c}\text { Amino acid } \\
\text { change }\end{array}$ & $\begin{array}{c}\text { Theoretical pI } \\
\text { (Isoelectric point) }\end{array}$ & $\begin{array}{c}\text { Aliphatic } \\
\text { index }\end{array}$ & Instability index & $\begin{array}{c}\text { Grand average } \\
\text { of hydropathicity (GRAVY) }\end{array}$ \\
\hline ND2 & & & & \\
Normal & 9.86 & 120.61 & 29.67 (stable protein) & 0.762 \\
p.(Ile86Val) & 9.86 & 120.32 & 29.67 (stable protein) & 0.761 \\
p.(Ile122Val) & 9.86 & 120.32 & 29.67 (stable protein) & 0.761 \\
p.(Arg176Gln) & 9.80 & 120.61 & 30.06 (stable protein) & 0.765 \\
p.(Ala185Thr) & 9.86 & 120.32 & 29.92 (stable protein) & 0.754 \\
p.(Asn197Ser) & 9.86 & 120.61 & 31.02 (stable protein) & 0.769 \\
p.(Val202Ile) & 9.86 & 120.89 & 30.23 (stable protein) & 0.763 \\
p.(Met220Thr) & 9.86 & 120.61 & 29.67 (stable protein) & 0.754 \\
ND4 & & & & \\
Normal & 9.58 & 131.37 & 37.22 (stable protein) & 0.801 \\
p.(Trp307Cys) & 9.53 & 131.37 & 37.12 (stable protein) & 0.809 \\
p.(Ile401Thr) & 9.58 & 130.52 & 37.22 (stable protein) & 0.790 \\
\hline
\end{tabular}

The results shown in Table 6 demonstrate that the non-synonymous mutations of the ND2 gene resulting in amino acid changes (p.(Ile86Val), p.(Ile122Val) and p.(Ala185Thr)) influenced the number of transmembrane sequences. In the three indicated cases, the number of transmembrane sequences decreased from ten to eight. The other non-synonymous mutations resulting in the change in the amino acid in the ND2 and ND4 proteins did not influence the number of transmembrane sequences (Table 6). The values of the expected number of amino acids in transmembrane helices, which substantially exceed the threshold value (18), allow an assumption that this may be a transmembrane protein or a signal peptide. The expected number of amino acids in the transmembrane helices in the first 60 amino acids of the protein (Exp number, first 60 AAs) was at a level of 35 AAs for the amino-acid substitutions of the ND2 protein and 25 AAs for the amino-acid substitutions of the ND4 protein. 


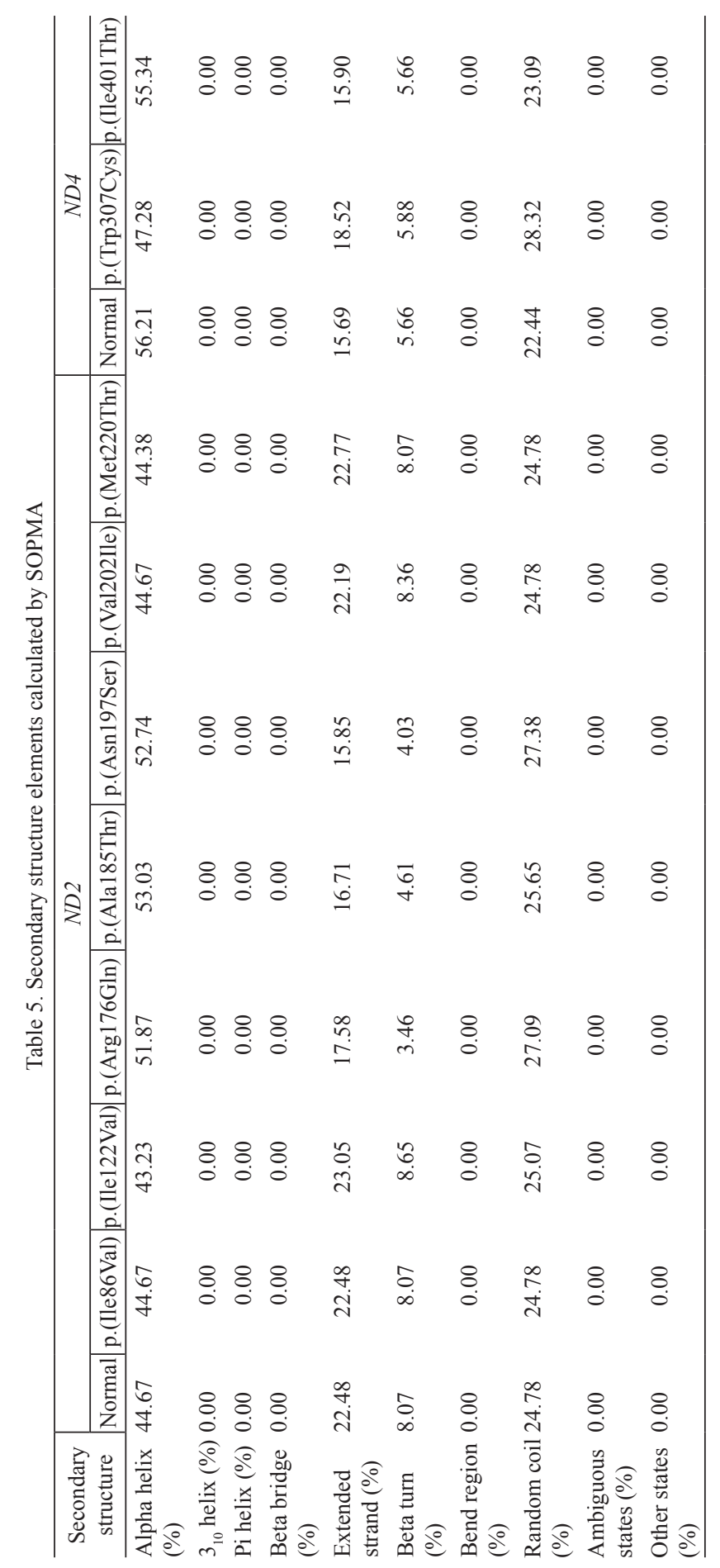


Table 6. Prediction of transmembrane helices in ND2 and ND4

\begin{tabular}{l|c|c|c|c}
\hline $\begin{array}{c}\text { Protein name/ } \\
\text { Amino acid change }\end{array}$ & $\begin{array}{c}\text { Length } \\
\text { (aa) }\end{array}$ & $\begin{array}{c}\text { Transmembrane } \\
\text { sequences }\end{array}$ & $\begin{array}{c}\text { Exp number of AAs } \\
\text { in TMHs }\end{array}$ & Exp number, first 60 AAs \\
\hline ND2 & & & & \\
Normal & 347 & 10 & 201.01 & 35.34 \\
p.(Ile86Val) & 347 & 8 & 201.28 & 35.47 \\
p.(Ile122Val) & 347 & 8 & 199.69 & 35.11 \\
p.(Arg176Gln) & 347 & 10 & 202.53 & 35.58 \\
p.(Ala185Thr) & 347 & 8 & 198.63 & 35.25 \\
p.(Asn197Ser) & 347 & 10 & 201.77 & 35.28 \\
p.(Val202Ile) & 347 & 10 & 200.86 & 35.33 \\
p.(Met220Thr) & 347 & 10 & 200.37 & 35.31 \\
ND4 & & & & \\
Normal & 459 & 12 & 271.88 & 25.47 \\
p.(Trp307Cys) & 459 & 12 & 271.49 & 25.47 \\
p.(Ile401Thr) & 459 & 12 & 271.88 & 25.47 \\
\hline
\end{tabular}

\section{Discussion}

Many mitochondrial DNA mutations determining human neoplasia and carcinogenesis have been described to date. As many as $25-80 \%$ of somatic mutations in mitochondrial DNA (mtDNA) have been found in various human neoplasms. It is assumed that these mutations are involved in neoplastic transformation via changes in cellular energy levels, enhancement of oxidative stress, and modulation of apoptosis (Ślaska et al., 2013; Grzybowska-Szatkowska and Ślaska, 2014; GrzybowskaSzatkowska et al., 2014).

Besides the association of mutations in the non-coding region (D-loop) with tumours (Slaska et al., 2014; Ślaska et al., 2014; Śmiech et al., 2016; Surdyka and Slaska, 2017 a), a defect was detected in several mtDNA genes (ND1, ND2, ND4, $C Y T B, C O X I, C O X 2, C O X 3$ and $A T P O$ ) in canine tumours. However, the investigations did not include MCTs (Slaska et al., 2015; Ślaska et al., 2016; Surdyka and Slaska, 2017 b), except for the analyses of the CYB gene in MCTs (Śmiech et al., 2019). Most of the pathogenic mutations in canine tumours were described as homoplasmy, although heteroplasmy was noted as well. The results obtained in this study are consistent with literature reports. Heteroplasmy was found only in one dog in the case of the ND2 gene and in two dogs in the case of the ND4 gene in MCTs (Table 2). The other causal mutations were homoplasmic (Table 2). The first study on the association of mutations in the mtDNA hypervariable region with MCTs (Śmiech et al., 2016) demonstrated that a majority of mutations and polymorphisms were homoplasmic. In two dogs only, blood and/or tumour heteroplasmy was detected in mast cell tumours (Śmiech et al., 2016). In turn, contrasting results, i.e. a high frequency of $C Y B$ gene heteroplasmy, were described by Śmiech et al. (2019). Het- 
eroplasmic mutations were detected in seven positions of mtDNA in $86 \%$ of individuals.

The investigations of mutations in canine mammary tumours demonstrated 11 polymorphisms in the ND2 gene sequence, which were all single-nucleotide substitutions (Surdyka and Slaska, 2017 b). Similarly, there were ten SNP polymorphisms in the MCTs (Table 3), with one described for the first time (m.4360T $>$ C) and the other identified in canine mammary tumours as well (Surdyka and Slaska, 2017 b). The polymorphism of the ND2 gene described in this study, besides m.4360T $>\mathrm{C}$, may be specific not only to MCTs but also to other canine tumours.

No mutation in the ND2 gene sequence was detected in canine mammary tumours (Surdyka and Slaska, 2017 b). Different results were obtained in the present study for the canine MCTs (Table 2). Twelve mutations were identified in the ND2 gene sequence, with six resulting in amino acid substitution in the protein (Table 2). These results may indicate a potential role of the ND4 protein in the etiopathogenesis of mast cell tumours.

The ND4 gene sequence was analysed in German Shepherd dogs with various types of tumours (Ślaska et al., 2016). Polymorphisms were detected in five nucleotide positions in those dogs. The polymorphisms in the canine MCTs were found in the same positions (Table 3); however, we identified six yet undescribed polymorphisms in the ND4 gene sequence in positions m.10773, m.10863, m.11172, m.11322, and $\mathrm{m} .11400$, which did not cause a change in the amino acid in the polypeptide chain, and one non-synonymous polymorphism in m.11121A > T (p.(Trp307Cys)) (Table 3). The mutations in German Shepherd dogs occurred in 10 positions of the ND4 gene (Ślaska et al., 2016), whereas the canine MCTs were characterised by mutations in seven positions of the ND4 gene. There were yet hitherto undescribed synonymous mutations in three positions of the ND4 gene (m.11172, m.11176, m.11241) (Table 2). Both the six newly detected polymorphisms in the ND4 gene sequence and the mutations in positions m.11172, m.11176, and m.11241 may be specific to MCTs (Tables 2 and 3).

The analysis of the main physicochemical protein parameters did not reveal significant differences in their values between the blood and the disease-affected tissue (Table 4). Most probably, despite the MCTs in the dogs, the proteins encoded by ND2 and ND4 retained their function. The secondary structure elements calculated by SOPMA (Table 5) did not exhibit changes in the percentage of the individual components of the secondary structure. The analysis of the secondary structure revealed that the $\alpha$-helix was dominant among the secondary structure elements, followed by random coils, extended strands, and $\beta$-turns for the sequences (Table 5). The dominance of the coiled regions indicates a high level of conservation and stability of the protein structure (Neelamathi et al., 2009).

These results differ from reports showing that mutations and polymorphisms in genes influence the function of proteins (Slaska et al., 2015; Ślaska et al., 2016), but are consistent with results showing no negative effect of the change in a single amino acid in the protein on its function (Slaska et al., 2015; Surdyka and Slaska, 2017 b).

Slaska et al. (2015) described a mutation in the ND1 gene sequence resulting in an amino acid change in the polypeptide chain (p.Thr193Asn) as well as a polymor- 
phism and mutations in the $C Y T B$ gene leading to an amino acid change (p.Val98Met, p.Val118Met, p.His196Pro) in various types of epithelial and mesenchymal canine tumours. All these were deleterious changes. Similarly, in the investigations of various types of tumours in German Shepherd dogs, non-synonymous mutations resulting in an amino acid change were detected (p.Gly239Val and p.Ile401Thr) in ND4 (Ślaska et al., 2016). The authors conclude that polymorphisms occurring in cells can have a negative impact on the protein function.

The present results (Tables 4-6) are in agreement with the results of investigations of two genes from respiratory complex IV in canine mammary tumours. Two mutations in the $C O X 2$ and $C O X 3$ genes resulting in an amino acid change were identified (p.Asn117Ser and p.Ala184Thr, respectively); however, the analyses indicated that proteins encoded by $C O X 2$ and $C O X 3$ retained their function (Surdyka and Slaska, 2017 b). Furthermore, no non-synonymous mutations were detected in some genes, i.e. COX1 (in different types of cancer) as well as ND2 and ATP6 (in canine mammary tumours) (Slaska et al., 2015; Surdyka and Slaska, 2017 b).

Based on the present results (Table 2), it can be concluded that the changes identified in the non-synonymous protein-coding SNPs do not exert a deleterious effect on the protein and electron transport chain. It is probable that although there was no significant effect of the amino acid changes in the described positions of genes ND2 and ND4 on the protein function, the total effect of the accompanying mutations and polymorphisms may have contributed to neoplastic transformation and promoted disorders in the energy level in cells and thus their potential role in carcinogenesis. As suggested by Wallace (2012), the absence of a functional effect of the nonsynonymous protein-coding SNP on the ND2 and ND4 protein can be explained by the fact that functional mitochondria are essential for the function of the tumour cell and do not inactivate metabolism but change the mitochondrial bioenergetic and biosynthetic state. Additionally, despite the absence of changes in the amino acid sequence of the polypeptide chain, non-synonymous mutations can disturb splicing and interfere in miRNA binding, causing changes in mRNA stability. This in turn can induce protein synthesis disorders, alter protein secondary structure, and modify protein activity by mediation of the induction of translation suppression (Nackley et al., 2006; Kimchi-Sarfaty et al., 2007; Parmley and Hurst, 2007).

The association of dogs' phenotypic traits and cancer traits with the occurrence of mutations and polymorphisms in ND2 and ND4 has been described in MCTs for the first time.

The statistical analyses demonstrated that the probability of the occurrence of polymorphisms and the appearance of nucleotide changes (mutations and polymorphisms) in position m.4204 of the ND2 gene and in position m.10992 of the ND4 gene was significantly higher in males than in females. Similarly, Śmiech et al. (2019) presented sex-specific polymorphisms in the cytochrome b gene in positions m.14474 and m.15010, which were only found in females, whereas polymorphism in m.14972 was detected only in males. No such relationships were recorded in the case of mutations in the non-coding hypervariable region of mtDNA in MCTs (Śmiech et al., 2016). 
The probability of occurrence of mutations and polymorphisms in the ND2 and ND4 gene sequences and position m.10992 was significantly lower in the youngest dogs compared with the middle-aged individuals. These results are in agreement with the findings presented by Śmiech et al. (2016), who noted association of mutations in the non-coding D-loop with the age of dogs. The authors described two mutations detected in dogs aged six years or older, but absent in the youngest dogs. Similarly, association of polymorphisms in position m.8242C $>\mathrm{T}$ of the ATP6 gene and $\mathrm{m} .7383 \mathrm{~T}>\mathrm{C}$ of the $C O X 2$ gene with older age was noted by Surdyka and Slaska (2017 a) in female dogs with mammary tumours.

Surprisingly, there were no significant correlations between the analysed mutations and polymorphisms of the ND2 and ND4 genes with the MCT malignancy grade. The mutations of the analysed mtDNA genes may occur in the first stage of tumour formation and may not be associated with the grade of neoplastic lesions. Similar results were presented by Śmiech et al. (2016) in their investigations of the sequence of D-loop non-coding regions in canine MCTs. The authors did not report any association of the presence of mutations with the tumour malignancy grades. In turn, subsequent analysis of mutations in the cytochrome b gene in MCTs (Śmiech et

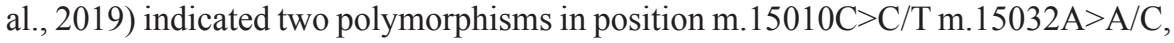
which were detected only in low-grade MCTs. These findings confirm the hypothesis proposed above.

In this study, the probability of the appearance of mutations and polymorphisms of the ND2 gene and in position m.4303 was evidently associated with the location of MCTs, i.e. it was significantly higher for tumours located on the extremities than on the torso. There was also a significantly more frequent occurrence of mutations and polymorphisms in position m.11172 in the representatives of large breeds, compared with the medium-sized dogs. Similarly, the results of investigations conducted in female dogs with mammary tumours (Surdyka and Slaska, 2017 b) demonstrated association of polymorphisms in position m.8242C $>\mathrm{T}$ of the ATP synthase F0 subunit 6 gene and $\mathrm{m} .7383 \mathrm{~T}>\mathrm{C}$ of the cytochrome $c$ oxidase subunit II gene with the large body size of dogs. The results of investigations of various types of canine tumours indicate possible associations of mutations with the location of tumours (Ślaska et al., 2016). The probability of occurrence of ND4 gene mutations in three loci (m.10917, m.11250, m.11402) in different tumours of internal organs and genital area was significantly higher than in mammary gland cancer (Ślaska et al., 2016).

This is the first literature report of mutations and polymorphisms in the mitochondrial DNA coding regions in the ND2 and ND4 genes in canine MCTs. Mutations and polymorphisms determining neoplastic transformation have been identified and mutations and polymorphisms specific to mast cells have been described for the first time. The changes identified in the non-synonymous protein-coding SNPs did not exert an adverse effect on the protein; however, the high prevalence of mtDNA mutations in canine mast cell tumours may indicate genetic instability of mtDNA, which may play a role in carcinogenesis. It should be emphasised that further investigations are necessary to determine specific mutations that can become molecular markers of MCTs in the future. 


\section{Ethics approval}

The study was approved by the II Local Ethical Commission for Animal Experiments in Lublin, Poland (Resolution number 6/2013).

\section{References}

Blackwood L., Murphy S., Buracco P., De Vos J.P., De Fornel-Thibaud P., Hirschberger J., Kessler M., Pastor J., Savary-Bataille K., Argyle D.J. (2012). European consensus document on mast cell tumours in dogs and cats. Vet. Comp. Oncol., 10: e1-e29.

Combet C., B la n chet C., Ge ourjon C., Dele ag e G. (2000). NPS@: network protein sequence analysis. Trends Biochem. Sci., 25: 147-150.

DNA Baser Sequence Assembler 3.2. Heracle BioSoft SRL Romania. (2012). http://www.DnaBaser. com.

Gasteiger E., Hoogland C., Gattiker A., Wilkins M.R., Appel R.D., B a iroch A. (2005). Protein identification and analysis tools on the ExPASy server. In: The proteomics protocols handbook. Humana Press, pp. 571-607.

Grzybowska-Szatkowska L., Ślaska B. (2014). Mitochondrial NADH dehydrogenase polymorphisms are associated with breast cancer in Poland. J. App. Genet., 55: 173-181.

Grzybowska-Szatkowska L., Ślaska B., Rzymowska J., Brzozowska A., F1or i a ń c z y k B. (2014). Novel mitochondrial mutations in the ATP6 and ATP8 genes in patients with breast cancer. Mol. Med. Rep., 10: 1772-1778.

Hendri c k M.J., M a h affe y E.A., M o or e J.H., Wa 1 d e r E.J. (1998). Histological Classification of Mesenchymal Tumors of Skin and Soft Tissues of Domestic Animals. In: WHO International Histological Classification of Tumors of Domestic Animals. Second Series. Washington: Armed Forces Institute of Pathology, 2: 28-29.

HGVS (2016). Recommendations for the description of sequence variants: 2016 update. Den Dunnen et al. 2016. Hum. Mutat., 37: 564-569.

K i m S.K., L e e S.E., J e o n g H., H a J.H. (1998). The complete nucleotide sequence of the domestic $\operatorname{dog}$ (Canis familiaris) mitochondrial genome. Mol. Phylogenet. Evol., 10: 210-220.

K i m c h i - S a rfat y C., O h J.M., K i m I.W., S a u n a Z.E., C a l c a g no A.M., A m bu d k a r S.V., G o t t e s m a n M.M. (2007). A "silent" polymorphism in the MDR1 gene changes substrate specificity. Science, 315: 525-528.

Kiupel M., Webster J.D., Bailey K.L., B est S., De Lay J., Detris ac C.J., Fitzgerald S.D., Gamble D., Ginn P.E., Goldschmidt M.H., Hendrick M.J. (2011). Proposal of a 2-tier histologic grading system for canine cutaneous mast cell tumors to more accurately predict biological behavior. Vet. Pathol., 48: 147-155.

K u mar S., S t e c h e r G., Ta mu r a K. (2016). MEGA7: Molecular Evolutionary Genetics Analysis version 7.0 for bigger datasets. Mol. Biol. Evol., 33: 1870-1874.

L e i d in ge r E.F., F re e m an K., K irtz G., Hoo ijberg E.H., S i ck K. (2014). Breed related odds ratio and anatomic distribution of canine mast cell tumours in Austria. Retrospective study of cases in the years 2000-2010. Tierarztl Prax. K. H., 42: 367-373.

Letard S., Yang Y., Hanssens K., Palmérini F., Leventhal P.S., Guéry S., Mous sy A., Kinet J.P., Hermine O., Dubreuil P. (2008). Gain-of-function mutations in the extracellular domain of KIT are common in canine mast cell tumors. Mol. Cancer Res., 6: $1137-1145$.

L u J., S h a rm a L.K., B a i Y. (2009). Implications of mitochondrial DNA mutations and mitochondrial dysfunction in tumorigenesis. Cell Res., 19: 802-815.

Nackley A.G., Shabalina S.A., Tchivileva I.E., Satterfield K., Korchynskyi O., Makarov S.S., Maixner W., Di a tchenko L. (2006). Human catechol-O-methyltransfer- 
ase haplotypes modulate protein expression by altering mRNA secondary structure. Science, 314 : 1930-1933.

Neelamathi E., Vasumathi E., Bagyalakshmi S., Kannan R. (2009). In silico prediction of structure and functional aspects of a hypothetical protein of Neurospora crassa. Cell Tissue Res., 9: 1889-1894.

P arm ley J.L., Hurst L.D. (2007). How do synonymous mutations affect fitness? Bioessays, 29: 515-519.

P ionnier-Capitan M., B e milli C., B od u P., C elerier G., Ferrie J.G., Fos s e P., G a r c i a M., Vig n e J.D. (2011). New evidence for Upper Palaeolithic small domestic dogs in SouthWestern Europe. J. Archaeol. Sci., 38: 2123-2140.

Slaska B., Grzybowska-Szatkowska L., Surdyka M., N is ztuk S., Różańska D., Różań s k i P., Ś mi e c h A., Orzels ki M. (2014). Mitochondrial D-loop mutations and polymorphisms are connected with canine malignant cancers. Mitochondr. DNA, 25: 238-243.

Slaska B., Grzybowska-Szatkowska L., Nisztuk S., Surdyka M., Rozanska D. (2015). Mitochondrial DNA polymorphism in genes encoding ND1, COI and CYTB in canine malignant cancers. Mitochondr. DNA, 26: 452-458.

Śla ska B., Grzybowska - S zatkowska L., B u gno-Poniewierska M., Surdyka M., Ś m i e ch A. (2013). Nuclear and mitochondrial DNA mutation in human and canine tumors. Med. Weter., 69: 195-202.

Ślaska B., Surdyka M., Brodzki A., Nisztuk S., Gurgul A., Bugno-Poniewiers k a M., Ś m i e c h A., Różań s k a D., Or zel s k i M. (2014). Mitochondrial D-loop mutations can be detected in sporadic malignant tumors in dogs. B. Vet. I. Pulawy, 631-637.

Ślaska B., Grzybowska-Szatkowska L., Bugno-Poniewierska M., Gurgul A., Śmi e ch A., Różańska D., Dudka J. (2016). Relevance of molecular changes in the ND4 gene in German Shepherd dog tumors. Pol. J. Vet. Sci., 19: 461-469.

S le d g e D.G., We bs te r J., Ki u p e l M. (2016). Canine cutaneous mast cell tumors: A combined clinical and pathologic approach to diagnosis, prognosis, and treatment selection. Vet. J., 215: 43-54.

Śmiech A., Ślaska B., Surdyka M., Grzybowska-Szatkowska L., Łopuszyńs k i W., R ó ża ń s k a D. (2016). Identification of additional mitochondrial DNA mutations in canine mast cell tumours. Acta Vet. Scand., 58: 28 .

Śmiech A., Ślaska B., Łopuszyński W., Jasik A., Szczepanik M., Wilkołek P. (2017). Epidemiological study of canine mast cell tumours according to the histological malignancy grade. Pol. J. Vet. Sci., 20: 455-465.

Śmiech A., Ślaska B., Łopuszyński W., Jasik A., Bochyńska D., Dąbrowski R. (2018). Epidemiological assessment of the risk of canine mast cell tumours based on the Kiupel two-grade malignancy classification. Acta Vet. Scand., 60: 70.

Śm i e ch A., Śla ska B., B ownik A., Grzybowska-S zatkowska L., Du dka J., Ło pus z yń s ki W. (2019). Heteroplasmic mutations and polymorphisms in the $C y b$ gene of mitochondrial DNA in canine mast cell tumors. In Vivo, 33: 57-63.

S u rd y k a M., S l a sk a B. (2017 a). Defect of the mitochondrial DNA hypervariable region as a risk factor for canine mammary tumor. Vet. Comp. Oncol., 15: 820-828.

S u rd y k a M., S 1 a s k a B. (2017 b). Defect in ND2, COX2, ATP6, and COX3 mitochondrial genes as a risk factor for canine mammary tumor. Vet. Comp. Oncol., 15: 1062-1072.

T ang H., Th o m a s P.D. (2016). PANTHER-PSEP: predicting disease-causing genetic variants using position-specific evolutionary preservation. Bioinformatics, 32: 2230-2232.

Vas ce 11 ari M., Giantin M., Cape 11 o K., Carminato A., More 11 o E.M., Verce 11 i A., Granato A., Bura c c o P., Da c a st o M., Mutinelli F. (2013). Expression of Ki67, BCL2, and COX-2 in canine cutaneous mast cell tumors: association with grading and prognosis. Vet. Pathol., 50: 110-121.

Wall a c e D.C. (2012). Mitochondria and cancer. Nat. Rev. Cancer., 12: 685-698.

Webster J.D., Yuzbas i y a -Gurkan V., Kane en e J.B., Miller R., Res au J.H., Kiupel M. (2006). The role of c-KIT in tumorigenesis: evaluation in canine cutaneous mast cell tumors. Neoplasia (New York, NY), 8: 104-111.

We bs ter J.D., Yuzb a s i y a n-Gurkan V., Mille r R.A., K a n e en e J.B., Ki u p e 1 M. (2007). 
Cellular proliferation in canine cutaneous mast cell tumors: associations with c-KIT and its role in prognostication. Vet. Pathol., 44: 298-308.

We 11 e M.M., B l e y C.R., H ow ard J., R ü fe n a c h t S. (2008). Canine mast cell tumours: a review of the pathogenesis, clinical features, pathology and treatment. Vet. Dermatol., 19: 321-339.

Received: 17 X 2019

Accepted: 27 II 2020 